\title{
REFORMA PROTESTANTE E EDUCAÇÃO ESCOLAR: AS CONTRIBUIÇÕES DE FELIPE MELANCHTHON (1497-1560)
}

\author{
PROTESTANT REFORMATION AND SCHOOL EDUCATION: \\ THE CONTRIBUTIONS OF PHILIP MELANCHTHON (1497-1560)
}

\author{
REFORMA PROTESTANTE Y EDUCACIÓN ESCOLAR: LAS \\ CONTRIBUCIONES DE FELIPE MELANCHTHON (1497-1560)
}

\author{
Rodrigo Pinto de Andrade ${ }^{\mathrm{I}}$ \\ Francielle Aparecida Garuti de Andrade ${ }^{\text {II }}$ \\ Cézar de Alencar Arnaut de Toledo ${ }^{\text {III }}$
}

Resumo Este texto tem como objetivo analisar as contribuições do teólogo alemão Felipe Melanchthon para a educação escolar no contexto da Reforma Protestante na Alemanha do século XVI. Embora tenha se voltado prioritariamente para as questões religiosas, a Reforma teve desdobramentos em outros campos da vida social e ultrapassou as questões relativas à igreja; reforçando movimentos de renovação nas mais diferentes esferas da estrutura social, inclusive o campo da educação escolar. Foi durante a Reforma Protestante que a ideia de uma educação voltada para todos começou a ser elaborada, essa educação, sob os auspícios da religião, tinha como objetivo possibilitar ao fiel o acesso aos textos bíblicos, assim, a educação era um elemento necessário para a disseminação da nova fé. As propostas educacionais dos reformadores do século XVI, em especial as de Melanchthon, estavam claramente ancoradas em pressupostos teológicos. Suas ideias pedagógicas eram de extração religiosa, que procuravam elevar a educação e a educação escolar ao patamar de determinantes para a consolidação da religião e para a renovação da sociedade. Amparado nos conceitos de sola scriptura e do sacerdócio universal de todos os crentes, Felipe

\footnotetext{
Universidade Estadual do Paraná (UNESPAR). Campo Mourão/PR - Brasil.

Universidade Estadual de Maringá (UEM). Maringá/PR - Brasil.

III Universidade Estadual de Maringá (UEM). Maringá/PR - Brasil.
} 
Melanchthon propôs a necessidade que os fiéis deveriam ter a capacidade de leitura dos textos bíblicos, precisariam para tal, receber educação.

Palavras-chave: Educação Escolar; Reforma Protestante; Felipe Melanchthon.

Abstract This text aims to analyze the contributions of the German theologian Philip Melanchthon to School Education in the context of the Protestant Reformation in Germany of the $16^{\text {th }}$ Century. Although it has focused primarily on religious issues, the Reformation had reached other fields of social life and overcame issues concerning the Church; reinforcing renovation movements in the most different spheres of social structure, including the school education area. It was during the Protestant Reformation that the idea of an Education for all the people began to be elaborated, this education, under the auspices of religion, intended to enable the faithful the access to biblical texts, thus, education was a necessary element for spreading the new faith. The educational proposals of the reformers of the sixteenth century, in particular those of Melanchthon, were clearly anchored in theological presuppositions. His pedagogical ideas were of religious extraction, which sought to raise education and the school education to the level of determinants for the consolidation of religion and the renewal of society. Supported by concepts of sola scriptura and the universal priesthood that all believers should have the ability to read the biblical texts, Philip Melanchthon proposed the necessity that the faithful should, for this purpose, receive the Education.

Key-words: School Education; Protestant Reformation; Philip Melanchthon.

Resumen Este texto tiene como objetivo analizar las contribuciones del teólogo alemán Felipe Melanchthon para la educación escolar en el contexto de la Reforma Protestante en la Alemania del siglo XVI. Aunque se ha orientado prioritariamente a las cuestiones religiosas, la Reforma tuvo desdoblamientos en otros campos de la vida social y sobrepasó las cuestiones relativas a la Iglesia; reforzando los movimientos de renovación en las más diversas esferas de la estructura social, incluyendo el campo de la educación escolar. Fue durante la Reforma Protestante, la idea de una educación orientada a todos comenzó a elaborarse, esta educación, bajo los auspicios de la religión, tenía como objetivo permitir al fiel el acceso a los textos bíblicos, así, la educación era un elemento necesario para la diseminación de la nueva fe. Las propuestas educativas de los reformadores del siglo XVI, en particular, las de Melanchthon, estaban claramente ancladas en supuestos teológicos. Sus ideas pedagógicas eran de extracción religiosa, que buscaban elevar la educación y la educación escolar al nivel de determinantes para la consolidación de la religión y para la renovación de la sociedade. Amparado en los conceptos de sola scriptura y del sacerdocio universal de todos los creyentes, Felipe Melanchthon propuso la necesidad que los fieles debían tener la capacidad de lectura de los textos bíblicos, deberían para ello, recibir educación.

Palabras clave: Educación escolar; Reforma Protestante; Felipe Melanchthon. 


\section{INTRODUÇÃO}

O objetivo deste texto é analisar a concepção de educação na obra do teólogo alemão Felipe Melanchthon e suas contribuições para o campo da educação escolar no contexto da Reforma Protestante na Alemanha do século XVI. Conhecido também como o "outro reformador de Wittenberg", Melanchthon ficou à sombra de Martinho Lutero (1483-1546) que, no Brasil, recebeu maior destaque e visibilidade. Suas propostas educacionais são pouco conhecidas entre nós, pois grande parte de sua obra ainda não foi traduzida para a língua portuguesa, por isso, sua atuação na construção de escolas e seu pensamento pedagógico foram pouco explorados. Todavia, sua obra contribuiu para o processo de consolidação e expansão dos pressupostos religiosos e educacionais da Reforma na Alemanha.

Para discutir a temática proposta, inicialmente será analisada a Reforma Protestante e a sua influência sobre as questões educacionais na Europa do século XVI. Em seguida, será descrita de maneira contextual a vida e a obra de Felipe Melanchthon, com particular destaque para a sua formação acadêmica a partir das bases humanistas. Por fim, serão abordadas as contribuições do reformador alemão à educação. Serão analisados os seus principais postulados religiosos e educacionais e a influência de sua obra na educação escolar da Alemanha do século XVI.

A Reforma Protestante esteve inserida em um amplo movimento de reformas que preludiavam uma nova configuração para o mundo medieval. Embora tenha se voltado prioritariamente para as questões religiosas, o movimento desencadeado por Martinho Lutero teve desdobramentos em outros campos da vida social e ultrapassou as questões relativas à igreja; reforçando movimentos de renovação nas mais diferentes esferas da estrutura social, inclusive o campo da educação escolar. Partindo do entendimento de que a educação não é um fenômeno isolado da sociedade, mas pode ser inserida na emaranhada estrutura das relações sociais, e resulta da forma como os homens estão organizados para a produção da vida material, pode-se dizer que a Reforma enquanto movimento social influenciou o contexto educacional do século XVI.

As propostas educacionais de Felipe Melanchthon estavam vinculadas a uma teologia que buscava libertar o homem de sua prisão religiosa. Amparado na doutrina de que todos os fiéis eram também sacerdotes, e por isso deveriam receber educação suficiente para estudar a Bíblia, Melanchthon, a exemplo dos demais reformadores da época, especialmente Martinho Lutero e João Calvino (1509-1554), propôs um modelo de educação popular voltada para todos, e não somente para o clero e para as elites como até então propunha a Igreja Católica. Ele foi o continuador das propostas religiosas de Lutero na Alemanha, considerado por muitos o Preceptor Germaniae, isto é, o professor da Alemanha, que auxiliou para a formação de um currículo e para as estruturas organizativas das escolas alemãs.

Felipe Melanchthon contribuiu para que a Alemanha discutisse o seu sistema de ensino, após a Reforma Protestante, e se ocupou com a questão da alfabetização dos leigos e prestou importante serviço à popularização do ensino mediante a abertura de escolas populares de ensino gratuito. Suas propostas educativas estiveram, ao mesmo tempo, alinhadas 
aos valores humanistas e aos ideais educativos da Reforma Protestante que tiveram desdobramentos na constituição do sistema educacional da Alemanha, no século XVI, como também ofereceram elementos que contribuíram para a constituição da Escola Moderna.

\section{REFORMA PROTESTANTE E EDUCAÇÃo}

O início da Reforma Protestante teve como marco definidor o período entre os anos de 1517 e 1555, respectivamente. A Alemanha foi o seu cenário inicial, e o monge agostiniano Martinho Lutero foi o seu principal expoente. A Reforma representou uma significativa transformação no campo da fé e marcou o fim do monopólio da autoridade da Cúria Romana na Europa ocidental. No decorrer de sua história, a igreja passou por largas transformações nos aspectos estrutural e doutrinário. Ela deixou de ser apenas uma comunidade de crentes fervorosos e seguidores de Jesus Cristo, para tornar-se uma instituição poderosa e secular que dominou a sociedade medieval europeia em quase todos os seus aspectos (REINHARD, 1989).

A elite medieval europeia estava vinculada direta ou indiretamente à Igreja Católica. $\mathrm{O}$ alto clero, liderado pelo papa, era composto por bispos, cardeais e arcebispos. A nobreza, composta por condes, duques e barões, estava submissa a príncipes, reis ou imperadores, que por sua vez, precisavam da religião católica para legitimar o seu poder e justificar a sua posição num mundo cujas bases era a fé. A igreja, portanto, controlava as várias esferas da vida social e possuía decisiva influência sobre toda a sociedade medieval europeia, domínio esse questionado e combatido pela Reforma Protestante do século XVI (VIEIRA, 2012).

O clima religioso do final da Idade Média retratava uma igreja cujos fiéis clamavam por mudanças. A cobrança de indulgências - o perdão dos pecados mediante o pagamento de emolumentos, prática que se acentuou no início do século XVI, e os abusos de poder cometidos pelo clero, apontavam para uma fragilidade nas estruturas administrativas da Igreja. As denúncias de vendas de funções eclesiásticas, sobretudo na Alemanha, causavam indisposição popular contra a Cúria Romana (ARNAUT DE TOLEDO, 1999).

A Reforma proposta por Lutero, em 1517, quando da divulgação das suas 95 Teses para o debate público, contra a venda de indulgências e com severas críticas aos clérigos, era a culminação de um processo de reivindicações por mudanças no interior da igreja. Antes de Lutero, podem ser destacados indivíduos como John Wicliff (1324-1384) e Jan Huss (1369-1415), entre outros, que propuseram mudanças na eclesiologia, porém, não obtiveram êxito (O’NEILL, 1991; FUDGE, 2004).

Os questionamentos de Martinho Lutero não eram inéditos, esses antecessores já os tinham apresentado. A proposta de retorno a um modelo da igreja da antiguidade já havia sido feita em vários momentos na história do cristianismo. O diferencial de Lutero foi o cenário político e econômico favorável à aceitação de suas propostas, que encontraram apoio entre os príncipes alemães. Estes também criticavam severamente o domínio da Cúria Romana em seus territórios. O desejo de se tornarem independentes de Roma e de se apropriarem de terras e propriedades da igreja também contribuiu para que apoiassem as propostas de Lutero (JANZ, 2004; SCASE, 2004; GARCÍA-VILLOSLADA, 1976). 
O apoio à causa reformatória teve várias frentes diferentes, são elas: a embrionária classe burguesa, descontente com os ensinamentos da igreja, que condenava o lucro e o sucesso material e os camponeses, que pleiteavam a emancipação do estado de servidão e depositaram nas propostas de Lutero as suas expectativas de transformação da realidade política e econômica. O movimento desencadeado pelos questionamentos de Martinho Lutero extrapolou os seus anseios iniciais e ganhou grande repercussão (GREEN, 1984).

Há que se ter clareza que todas as mudanças pelas quais passou a igreja no Ocidente, no século XVI, não surgiram espontaneamente nesse mesmo século. Todas as propostas de mudanças tinham um longo histórico, tanto na esfera teológica, dentro da própria igreja, como econômica, fora dela. Tais fatores pressionavam por mudanças em suas estruturas. Por isso, não é possível falar em Reforma como um evento, como um fato coeso, mas, há que se considerar o termo numa maior extensão. Trata-se de um movimento que esteve inserido em um amplo movimento de reformas que preludiavam uma nova configuração para a religião cristã, em crise. A Reforma, portanto, fez parte do marco das rachaduras provocadas pela ação histórica dos homens na estrutura da sociedade medieval e contribuiu, como elemento importante, na transição do feudalismo para o capitalismo comercial. Não era apenas a religião que passava por mudanças, no século XVI, mas também as demais áreas da vida social dos homens estavam em transformação no período (CHAUNU, 1984; TAWNEY, 1971).

A religião deve ser analisada para além de seus próprios limites, ou seja, precisa ser concebida numa relação com o modo de produção e reprodução da vida humana (MARX, 1983). Partindo dessa compreensão, a Reforma Protestante, embora tenha se voltado prioritariamente às questões eclesiásticas, teve desdobramentos em outros campos da vida social e ultrapassaram as questões relativas à igreja; reforçando movimentos de renovação nas mais diferentes esferas da estrutura social, inclusive as questões relacionadas à educação escolar. As ideias religiosas defendidas pelos reformadores aproximaram os textos bíbli$\cos$ dos fiéis. Ao ensinarem que a salvação seria alcançada por meio do conhecimento da Palavra de Deus, os reformadores protestantes estavam propondo que seria necessário que os fiéis fossem capazes de ler os Textos Sagrados para receberem a salvação, para tal, eles buscaram incentivar o ensino, pois a continuidade da Reforma dependeria da capacidade de ler e escrever dos adeptos do movimento. A educação, portanto, se apresentava como fator preponderante para o avanço das propostas protestantes.

A partir da Reforma Protestante, a educação escolar foi colocada a serviço da religião e da fé. Francisco Larroyo chama essa atitude de "teísmo pedagógico", isto é, o propósito final do processo educativo era ser o mediador nas relações com Deus e a sua revelação (Bíblia). A proposta dos reformadores do século XVI era aplicar a própria razão à verdade divina, contida nos evangelhos, para tal, exigia-se que todos soubessem ler a Bíblia, isto apresentou às instituições da sociedade responsáveis pela escolarização da população, o problema de uma educação geral, para todos, sem distinção de idade, classe social, raça e sexo (LARROYO, 1982).

No caso de Martinho Lutero, a educação foi apresentada como requisito fundamental para o Reino de Deus e para a consolidação de uma sociedade mais igualitária. Em 
sua percepção, o bom cristão deveria ser também um bom cidadão, que cumpria as leis e obedecia às autoridades. Ele defendeu que a educação era fundamental na realização do verdadeiro cristianismo. O modelo de educação preconizado por Lutero objetivava formar um homem obediente às leis civis, que conhecesse as leis divinas, pelo estudo diário da Escritura e que servisse ao próximo pela ética do amor, decorrentes da fé em Cristo, o Salvador (DREHER, 2002).

O processo educativo foi apresentado pelos reformadores como uma via nas relações com Deus e com a sua revelação, a Bíblia sagrada. Os conceitos teológicos do sacerdócio universal de todos os crentes e do princípio da Sola Scriptura exigiam que os adeptos da nova fé soubessem ler e interpretar os Textos Sagrados, o que acabou por trazer à tona o debate sobre a necessidade de uma educação elementar, para todos, sem distinção de idade, classe social, raça e sexo (ARNAUT DE TOLEDO; VIEIRA, 2011).

Era necessário que o fiel soubesse ler e entender a Escritura Sagrada, o que aponta para a importância da educação, que se daria por meio da instrução e do ensino das verdades da fé; para tal, os reformadores propuseram que todos deveriam ter acesso à Bíblia na língua vernácula. Como afirma Paulo Henrique Vieira, "ao incentivar as traduções da bíblia para as línguas vernáculas, os reformadores ampliaram a possibilidade de compreensão de um mundo que estava ainda muito ligado aos dogmas e aos ensinos do Cristianismo" (VIEIRA, 2012, p. 9).

Para os reformadores do século XVI, a educação adquiriu uma importância muito grande, pois educar, num primeiro momento, era um ato relacionado à fé e à salvação, e estava no âmbito da religião, porém, logo depois, foi assumindo, pouco a pouco, um caráter de preparação para o novo mundo trabalho (ARNAUT DE TOLEDO, 1999).

Podemos dizer que a proposta de educação por eles preconizada objetivava formar um homem obediente às leis civis, que conhecesse as leis divinas, pelo estudo diário das Escrituras Sagradas e que servisse ao próximo, pela ética do amor, decorrentes da fé em Jesus Cristo. Por isso, a educação deveria estar subordinada à fé e precisaria ser construída a partir de uma rígida disciplina.

\section{FELIPE MELANChTHON (1497-1560): VIDA E OBRA DO REFORMAdOR ALEMÃo}

Felipe Melanchthon nasceu em Bretten, na Alemanha, em 16 de fevereiro de 1497, e seus pais eram de formação cristã. Filho de Georg Schwarterdt (ferreiro de armas e chefe das armas daquela cidade) e Barbara Reuter. Sua mãe era filha de Hans Reuter, comerciante e prefeito, cidadão ilustre de Bretten e de Elisabeth Reuchlin de Pforzheim, irmã de Johannes Reuchlin (1455-1522) que foi provavelmente, com Erasmo de Roterdã (1466 [?]-1536), um dos humanistas mais conhecidos ao norte dos Alpes, dando grandes aportes ao estudo do hebraico bíblico e à liberdade de investigação científica. Desde a adolescência Melanchthon teve contato com a Bíblia e com a gramática grega (WRIEDT, 2011; KLUG, ULRICH, 2016). 
Sobrinho-neto de Reuchlin, Filipe Schwarzerd cognominado Melanchthon, "terra negra", foi um humanista - foi por isso que traduziu o seu nome para o grego. Seu pai, George Schwartzerd, morreu quando Melanchthon tinha 11 anos de idade. Na época, ele foi encaminhado a Spire, local onde recebeu instruções do professor John Unger de Pforzheim, o qual possuía bom conhecimento das línguas antigas, grego, hebraico e latim. Foi educado nos moldes do humanismo com sólida formação na filosofia aristotélica (DANIEL-ROPS, 1996).

Aos 13 anos de idade, Melanchthon matriculou-se na faculdade de filosofia na Universidade de Heidelberg, onde ganhou a reputação de grande conhecedor de grego e firmou a sua reputação como excelente gramático e, depois, como humanista bíblico. Em 11 de junho de 1511, recebeu o grau de bacharel nas Artes Liberais. Em seguida, transferiu-se para a Universidade de Tübingen, onde recebeu o título de Magister Artium, em 25 de janeiro de 1514 e logo passou a lecionar nessa mesma universidade até 1518 (SILVA, 2010).

Aos 21 anos de idade, em 1518, Felipe Melanchthon tornou-se professor da Universidade de Wittenberg ${ }^{1}$ na área de língua e literatura grega. Ao chegar em Wittenberg, em seu primeiro discurso, na aula inaugural de 1518, De corrigendis adolescentiae studiies, (Melhoria da educação para os jovens), defendeu a reorientação do estudo dos clássicos como vinha sendo feito até então e apontou para a necessidade de um retorno ao estudo das línguas clássicas, especialmente hebraico e grego (RUPP, 1996).

Em Wittenberg, Felipe Melanchthon, sob a influência de Martinho Lutero, estudou teologia e se tornou partidário da Reforma. Embora nunca tenha sido ordenado para funções eclesiásticas, em Wittenberg foi professor de teologia no período de 1518 a 1560. Foi uma personagem importante no processo de formação dos líderes e pensadores do nascente movimento luterano. Com a morte de Lutero, em 1546, ele assumiu a liderança teológica do movimento (KLUG, ULRICH, 2016; KOLB, 1997).

Em 1521, publicou o livro Loci Communes Rerum Theologicarum (Princípios básicos de teologia), sendo a primeira obra sistemática da teologia do embrionário movimento protestante. O título Loci (tratado) indica uma contraposição ao termo Summen (completo), método comumente utilizado no período medieval. Os Loci não eram tratados fechados, mas abertos. De acordo com Kuropka, o diferencial dessa obra é o fato de ter sido modificada/retrabalhada por Melanchthon, muitas vezes, por exemplo, 1535, 1545 e 1559. O Loci Communes era como uma obra aberta, acrescida sempre de novas informações (KUROPKA, 2010).

Felipe Melanchthon foi também o autor de outro importante documento para a teologia da Reforma, a Confissão de Augsburgo (Confessio Augustana). Esse documento foi apresentado ao imperador no dia 25 de junho de 1530 e estava assinado por sete príncipes e pelos representantes de duas cidades livres. A Confissão de Augsburgo adquiriu imediata-

\footnotetext{
A Universidade de Wittenberg foi criada, em 1502, pelo Príncipe Eleitor da Saxônia Frederico III e foi reconhecida pelo papa somente em 1508. A universidade tinha três faculdades principais: direito, medicina e teologia. A criação de uma universidade também demonstrava o poder do príncipe daquele reino. À época, a Alemanha era parte do Sacro Império Romano-Germânico, estava dividida em diversos reinos, os quais rivalizavam entre si (SCHEIBLE, 2013).
} 
mente a importância peculiar de uma declaração pública de fé (LIVRO DE CONCÓRDIA, 1980; BIRNSTEIN, 2010; RHEIN et al., 1998).

Contudo, dois dias após a apresentação da Confissão, os representantes católicos resolveram preparar uma refutação à declaração luterana, a Confutatio Pontifícia, que foi lida na Dieta, em 3 de agosto. O imperador exigiu que os luteranos admitissem que a sua Confissão tinha sido refutada. A reação luterana surgiu na forma da Apologia da Confissão de Augsburgo, documento que também foi redigido por Felipe Melanchthon, ficando pronta para ser apresentada no dia 22 de setembro de 1530, porém, foi rejeitada pelo imperador, e só foi publicada por Melanchthon em maio de 1531, tornando-se a confissão de fé oficial do luteranismo, com a Confissão de Augsburgo. O documento foi assinado por sete príncipes, manifestando, assim, expresso apoio ao texto confessional, conferindo-lhe autoridade para não ser questionado dentro daquela região compreendida pelos príncipes que o assumiram (LIVRO DE CONCÓRDIA, 1980; KLUG, ULRICH, 2016; BIRNSTEIN, 2010).

Melanchthon foi o amigo mais próximo de Martinho Lutero e continuador de suas ideias na Alemanha. Lutero o conheceu em 1518 e tornou-se, conforme sua própria declaração, seu amigo até a morte, acompanhando-o em todas as fases da Reforma, especialmente no período em que Lutero traduziu a Bíblia para a língua alemã, tornando-se seu consultor sobre o idioma grego. Em relação à questão da educação, há que se destacar que as propostas de Lutero a respeito da forma de organização da educação escolar: colégios de ensino secundário, universidade e a proposta de criação de escolas elementares foram diretamente influenciadas por Melanchthon, considerado um dos mais eruditos mestres da Reforma alemã (BARBOSA, 2007; SILVA, 2010; EBY, 1976).

Alinhado às propostas de Erasmo de Roterdã, Felipe Melanchton propôs um modelo educacional claramente ancorado nos princípios humanistas da antiguidade clássica, no humanismo bíblico, bem como, na obra de padres gregos e latinos. Esse programa de educação Melanchton, fundamentado em pressupostos humanistas e teológicos, tinha elementos inéditos, não estando diretamente relacionado às propostas religiosas de Lutero e de outros teólogos do incipiente movimento reformado (FRIEDRICH; VOGEL, 1998). ${ }^{2}$

Felipe Melanchthon pode ser considerado o "pedagogo da Reforma luterana" (LUZURIAGA, 2001). Vanderlei Defreyn salienta que "[...] mais do que Lutero, seu amigo Melanchthon foi decisivo na elaboração de livros didáticos e na organização de ginásios e universidades e, na formação de professores" (DEFREYN, 2004, p. 82). Horst Rupp destaca que, em relação às questões educacionais, Felipe Melanchthon deve ser considerado, com toda justiça, o principal protagonista educacional da Reforma no século XVI, sendo inclusive, quem influenciou diretamente as ideias de Lutero sobre a educação escolar. O título de "Preceptor Germaniae", atribuído a Melanchthon, demonstra a sua importância

2 No original: "Im Anschluss an Gedanken des Erasmus von Rotterdam proklamierte Melanchton eine Bildungs- und Studienreform, die auf die humanistischen Grundsätzen der klassischen Antike, des Bibelhumanismus sowie der intensive Nutzung der griechischen und lateinischen Kirchenväter basierte. Dieses Programm hatte zunächst noch nichts mit der neuen Theologie zu tun, die Luther und seine Freunde damals in Wittenberg proklamierten. Was Melchanton jetzt vortrug, war sein Eigenes, das sich dann allerdings durchaus in die reformatorische Theologie integrieren liess" (FRIEDRICH; VOGEL, 1998, p. 14). 
como educador e mestre da Reforma Protestante na Alemanha (RUPP, 1996). ${ }^{3}$

Melanchthon foi um teólogo que, além de escrever sobre temas relativos à religião, escreveu também a respeito de assuntos seculares, entre os quais se destaca a educação. Influenciado pelo contexto das propostas educacionais da Alemanha do século XVI, e pelo humanismo, Melanchthon elaborou, a "Programação de Estudos Proposta a André Polônio por Felipe Melanchthon" (Ratio Studiorum Praescripta Andreae Polono a Philippo Melanchthone-[s.d.]), que serviu de base de estudos para muitas escolas europeias. Esse cronograma apresentava propostas de atividades para todos os dias da semana, com horários bem definidos e foi elaborado com base nos autores clássicos da antiguidade, Marco Terêncio Varrão e Marco Túlio Cícero (SILVA, 2010).

Ricardo Willy Rieth afirma que entre a sua vasta obra destaca-se um elevado número de cartas, ultrapassando a marca de dez mil missivas publicadas (RIETH, 1997). Dos textos de Melanchthon disponíveis em português, sobressaem: "A Confissão de Augsburgo", importante documento da Igreja Reformada, que contém 28 artigos com as principais doutrinas do luteranismo, Daniel-Rops diz que "é na confissão de Augsburgo que se deve procurar o pensamento total de Lutero e a essência do luteranismo" (DANIEL-ROPS, 1996, p. 309). Também, merece destaque o texto de Melanchthon, traduzido por Walter Hesse, "Lutero visto por um amigo", publicado, em 1983, pela editora Concórdia. Outros textos escritos por ele estão disponíveis em alemão, latim e inglês.

\section{As contribuições de Felipe Melanchthon à educaÇão escolar}

Os reformadores protestantes do século XVI, a partir de Lutero, passando por Calvino e inclusive Felipe Melanchthon, insistiram que o bom cristão deveria ser também um bom cidadão, isto é, precisaria, por meio da escolarização, adquirir a necessária disciplina para cumprir as leis e obedecer às autoridades. A educação, nesse sentido, constituiria um elemento fundamental na realização do verdadeiro cristianismo.

As propostas educacionais de Melanchthon são tributárias de uma concepção antropológica de feição religiosa, voltada para a questão da origem, causa e finalidade do ser humano, consideradas por ele, essenciais para o desenvolvimento de uma ação pedagógica proveitosa (RUPP, 1996). Segundo James William Richard, Melanchthon defendia a necessidade de levar os alunos às fontes originais. Ele ensinou sobre vários temas relacionados à teologia e à filosofia. Lecionou Hebraico, Latim, Grego, Gramática, Retórica, Física e Filosofia (RICHARD, 1898).

Muitas das escolas protestantes do século XVI foram fundadas com base nos princípios pedagógicos instituídos por Felipe Melanchthon, que elaborou normas escolares,

3 No original: "El hombre generalmente considerado y con toda justicia como el principal protagonista de la Reforma alemana en lo referente a la educación en el s. XVI, es Philipp Melanchton, el colaborador más próximo de Lutero en Wittenberg a partir de 1518. Es casi seguro que las propias ideas de Lutero sobre la educación procedían en gran medida de él. El título honorario de "Preceptor Germaniae" (maestro de Alemania) que se le concedió ya al principio de su carrera, demuestra su importancia como educador y maestro en la Reforma alemana" (RUPP, 1996, p. 4). 
organizou muitos cursos e nomeou professores para as primeiras escolas protestantes. Em 1524, o reformador elaborou um programa escolar com a seguinte proposta: na classe elementar, os alunos deveriam aprender os primeiros passos da alfabetização, a leitura em latim e de textos religiosos, como o Pai Nosso, o Credo, e os textos bíblicos. Na segunda classe, estava no currículo a gramática latina, bem como, a leitura e a memorização de comédias do pensador romano Titus Maccius Plautus (254-184 a.C.). Na terceira classe, os alunos deveriam estudar dialética e retórica, com base em um livro de Erasmo de Roterdã (JOESTEL; SCHORLEMMER, [s/d]) ${ }^{4}$

Felipe Melanchthon foi o elaborador das estruturas organizativas e dos conteúdos culturais próprios das escolas do período da Reforma Protestante do século XVI. Suas propostas foram mais direcionadas ao Ensino Secundário, podendo ser caracterizado como o inspirador da escola secundária pública alemã. Sua contribuição para o currículo do Ensino Secundário merece ser destacada, pois Melanchthon fundiu os ideais da Reforma e a cultura humanista na elaboração de currículos para essa modalidade de ensino (CAMBI, 1999; LUZURIAGA, 1975).

Isabel Gutierrez Zuluaga afirma que o mérito do reformador foi introduzir os estudos humanistas na educação secundária, além de elaborar um plano de ensino (ratio studiorum) que serviu de modelo a um grande número de escolas alemãs (ZULUAGA, 1972).

Até mesmo o conceito de piedade erudita, elemento essencial no processo educativo alemão é derivado das propostas educacionais de Melanchthon (GILES, 1987). Os pesquisadores alemães Joestel e Schorlemmer afirmam que a grande influência exercida por Melanchthon foram os seus livros escolares. Ele elaborou diversos livros, compôs gramáticas de língua latina e língua grega, livros didáticos de dialética e retórica. Até mesmo os jesuítas tiveram que, mais tarde, na construção de uma educação católica, utilizar os livros de Melanchthon, porque, inicialmente, não tinham os seus (JOESTEL; SCHORLEMMER, [s/d]). ${ }^{5}$

Entre os anos 1527 e 1528, Melanchthon foi o inspetor das escolas da Igreja da Saxônia e redigiu o regulamento para essas instituições. Esse documento tornou-se o primeiro dos muitos códigos mais tarde adotados pelas cidades e pelos Estados alemães no século XVI. Consta desse regulamento que as autoridades civis deveriam manter as escolas que, por sua vez, tinham o dever de preparar homens para as profissões eclesiásticas e civis (VIEIRA, 2005). Cada cidade deveria organizar suas escolas dividindo os alunos em três grandes grupos. Nas palavras do próprio Melanchthon, citadas por Mario Manacorda:

4 No original: "1524 entwarf er ein [...] einfaches Schulprogramm. [...] In der Elementarklasse wurden das $\mathrm{ABC}$, Lesen in Latein sowie religiöse Texte wie das Vater Unser, das Ave Maria, das Glaubensbekenntnis und Bibeltexte gelernt. In der 2. Klasse standen lateinische Grammatik sowie das Lesen und Auswendiglernen von Komödien des Terenz und des Plautus auf dem Lehrplan. In der 3. Klasse lernten die Schüler Dialektik und Rhetorik nach einem Lehrbuch des Erasmus. Im Geschichtsunterrricht wurden Livius und Sallust, dazu Vergil, Horaz und Ovid gelesen" (JOESTEL; SCHORLEMMER, [s/d], p. 21).

5 No original: "Er vermittelte Schulmeister und gab praktische Ratschläge. Grosse Einfluss übte Melanchton durch seine Schulbücher aus. Für viele Fächer hat er Lehrbücher verfasst: Grammatiken der lateinischen und griechischen Sprache sowie Lehrbücher der Dialektik und Rhetorik. Sogar die Jesuiten mussten später beim Aufbau eines katholischen Schulwesens Melanchtons Lehrbücher verwenden, da sie anfänglich keine eigenen hatten" (JOESTEL; SCHORLEMMER, s/d, p. 21). 
Antes de tudo uma cidade bem ordenada precisa de escolas, onde as crianças, que são o viveiro da cidade, sejam instruídas: engana-se gravemente, de fato, quem pensa que sem instrução possa adquirir-se uma sólida virtude e ninguém é suficientemente idôneo para governar as cidades sem o conhecimento daquelas letras que contêm o critério do governo de todas as cidades (MELANCHTHON, apud MANACORDA, 1992, p. 198).

De acordo com Ricardo Willy Rieth, entre as contribuições que Felipe Melanchthon legou à educação, destacam-se: a exigência de se saber um idioma estrangeiro, especialmente o latim e o grego; pensar e agir eticamente como objetivo dos esforços pedagógicos; cada ensino em particular faz parte de um todo; a ênfase na memorização e nos estudos das obras e línguas clássicas; a convergência entre humanismo e luteranismo (RIETH, 1997).

O reformador alemão reconheceu que a educação era um instrumento fundamental para a consolidação e difusão das doutrinas da fé protestante; isso justifica o seu engajamento na construção de escolas e elaboração de propostas destinadas à educação escolar. Em um de seus textos sobre filosofia e educação, escrito em 1537, Melanchthon afirma:

Vamos colocar isso diante de nós mesmos e perante outros, a fim de impressionar a nós, bem como outros, que as escolas são necessárias para a conservação da piedade, da religião, da ordem civil e também para a administração do estado (MELANCHTHON, 1999, p. 20. Tradução dos autores). ${ }^{6}$

Deve ser evidenciado que Felipe Melanchthon foi, sobretudo, um teólogo, por isso, suas preocupações educativas estavam alinhadas com as suas pretensões religiosas. Klaus Engelhardt destaca que, para Melanchthon, a ignorância era a maior inimiga da fé, por isso deveria ser combatida por meio da reforma das escolas, e da recuperação da autoridade cultural e moral dos educadores (ENGELHARDT, 1997). Werner Wiater ressalta que a teoria da educação proposta por Felipe Melanchthon uniu aspectos formais da educação (gramática, retórica, dialética), com aspectos materiais (sua seleção de literatura clássica) para formar uma educação no sentido da fé, que seria a preparação antropológica para as atividades do Espírito Santo e as ações responsáveis fiéis (WIATER, 1998). ${ }^{7}$

Evidencia-se que os escritos de Melanchthon influenciaram na elaboração de livros didáticos e currículos. As autoridades municipais solicitavam, ao reformador, orientações sobre a criação e a condução de escolas. De acordo com Franco Cambi, "a elaboração das estruturas organizativas e dos conteúdos culturais próprios das escolas secundárias da Reforma é devida, sobretudo, a Felipe Melanchthon" (CAMBI, 1999, p. 250).

6 No original: "Let us lay this before ourselves and before others, in order to impress on ourselves as well as others that the schools are necessary for the conservation of piety, religion, civil order and also for the administration of the state" (MELANCHTHON, 1999, p. 20).

7 No original: "Melanchthon's theory of education joins together formal aspects of education (grammar, rhetoric, dialectic) with material aspects (his selection of classical literature) to form an education in the sense of faith, that is the anthropological preparation for the activities of the Holy Ghost and the glory of God and the responsible actions of Christian people" (WIATER, 1998, p. 66). 
Sobre a importância de Melanchthon para a instituição da educação escolar na Alemanha do século XVI, Horst Rupp salienta que a sua influência foi igualmente duradoura no âmbito da reforma das universidades alemãs, onde também os seus conselhos foram sempre muito bem acolhidos. Como exemplo disso, é possível citar as universidades de Tubing, Frankfurt, Leipzig e Heidelberg (RUPP, 1996). ${ }^{8}$

Felipe Melanchthon foi reitor na Universidade de Wittenberg no período de 1523 a 1524; entre as medidas por ele adotadas, destacou-se a implementação de um novo regulamento de estudos para a Universidade, promulgado em 10 de janeiro de 1526. Claudete Beise Ulrich e João Klug afirmam que "no regulamento universitário proposto por Melanchthon percebe-se uma preocupação com o processo educativo individual de cada aluno. A tutoria é vista como um auxílio pedagógico no planejamento dos estudos" (ULRICH, KLUG, 2016, p. 161).

No regulamento universitário que Melanchthon propôs, aparece uma clara preocupação com o processo educativo individual. Nesse sentido, a atividade de tutoria foi apresentada no documento como um auxílio pedagógico no planejamento dos estudos. Para Melanchthon, o processo educativo estaria diretamente relacionado com a vivência, isto é, constitúa-se como fundamental o acompanhamento e o planejamento diário do aluno, garantindo que esse fosse moldado por rígidos valores morais de feição cristã (SCHEIBLE, 2013; ULRICH, KLUG, 2016).

\section{CONSIDERAÇõES FINAIS}

A Reforma Protestante, com outros fatores sociais, culturais e econômicos, como o Humanismo, o Renascimento, a urbanização, as grandes navegações e as transformações econômicas que estavam ocorrendo na Europa, constituíram-se em elementos determinantes para a configuração da educação escolar no início dos Tempos Modernos. Os reformadores religiosos do século XVI defenderam propostas que apontavam para a necessidade de que os fiéis tivessem condições de ler e entender a Escritura Sagrada, o que aponta para a importância da educação, que se daria por meio da instrução e do ensino das verdades da fé, para tal, todos deveriam ter acesso à Bíblia na língua vernácula.

Para Felipe Melanchthon, o conhecimento científico não tinha um fim em si mesmo, mas, deveria estar a serviço da teologia e do conhecimento de Deus, por isso, procurou definir uma proposta educativa que contemplasse princípios e valores do cristianismo e do humanismo: orações diárias, leitura de textos bíblicos e o estudo de textos clássicos. Sua teoria da educação buscou integrar os princípios do humanismo com as doutrinas religiosas da Reforma Protestante. Ele defendeu a importância do estudo dos textos gregos clássicos, afirmando que estes civilizavam e humanizavam.

\footnotetext{
8 No original: "Su influencia fue igualmente duradera en el ámbito de la reforma de las universidades alemanas, donde también sus consejos fueron siempre muy bien acogidos. Como ejemplo de esto se pueden citar las universidades de Tubinga, Francfort del Oder, Leipzig y Heidelberg” (RUPP, 1996, p. 7).
} 
A obra de Melanchthon contribuiu para a consolidação e a continuidade da Reforma e dos postulados protestantes acerca da educação escolar na Alemanha. Pode-se afirmar que Felipe Melanchthon, como um homem de seu tempo, desenvolveu uma concepção de educação claramente ancorada nos pressupostos teológicos e doutrinários do protestantismo e proclamou ideias pedagógicas de extração religiosa, que procurou elevar a educação e a educação escolar ao patamar de determinantes para a consolidação da religião e para a renovação da sociedade.

Felipe Melanchthon teve decisiva atuação no desenvolvimento de um modelo educacional elaborado para atender às demandas das novas teorias religiosas que estavam sendo adotadas na Alemanha durante o século XVI. Sua concepção educacional, além das interferências dos postulados teológicos, recebeu influência dos pensadores humanistas e de autores clássicos, utilizados como referências em seu Plano de Estudos.

\section{REFERÊNCIAS}

ARNAUT DE TOLEDO, Cézar de Alencar. A questão da educação na obra de Martinho Lutero. Acta Scientiarum, Maringá, n. 21, v. 1, p. 129-135, 1999.

ARNAUT DE TOLEDO, César de Alencar; VIEIRA, Paulo Henrique. O tema do Calvinismo nos manuais de história da educação. Disponível em: <http://www.faced.ufu.br/ colubhe06/anais/arquivos/90PauloHenriqueVieira_CezarArnautToledo\%20.pdf $>$ Acesso em: 17 jun. 2011.

BARBOSA, Luciane Muniz Ribeiro. Igreja, Estado e educação em Martinho Lutero: uma análise das origens do direito à educação, 246s. Dissertação. (Mestrado em Educação.) Universidade de São Paulo, 2007.

BIRNSTEIN, Uwe. Der Humanist: was Philipp Melanchthon Europa lehrte. Berlin: Wichern, 2010.

CAMBI, Franco. História da pedagogia. São Paulo: Editora Unesp, 1999.

CHAUNU, Pierre. 1984. Les temps des Réformes, 2. vol. Bruxelles: Éditions Complexe, 1984.

DANIEL-ROPS, Henri. A Igreja da Renascença e da Reforma (I). São Paulo: Quadrante, 1996. DREFREYN, Vanderlei. A tradição escolar luterana: sobre Lutero, educação e a história das escolas luteranas até a Guerra dos Trinta Anos, 150s. Dissertação (Mestrado em Teologia). Pós-Graduação em Teologia, Escola Superior de Teologia de São Leopoldo, São Leopoldo, 2004.

DREHER, Martin. A Crise e a Renovação da Igreja no Período da Reforma. Sinodal: São Leopoldo, 2002.

EBY, Frederick. História da educação moderna. Porto Alegre: Editora Globo, 1976. 
ENGELHARDT, Klaus. Filipe Melanchthon e sua importância para as Igrejas da Reforma. Estudos Teológicos. São Leopoldo, v. 37, n. 3, p. 236-242, 1997.

FRIEDRICH, Reinhold; VOGEL, Klaus A. 500 Jahre Philipp Melanchthon (1497-1560). Wiesbaden: Harrassowitz Verlag, 1998.

FUDGE, Thomas A. Hussite theology and the law of God. In: BAGCHI, D.; STEINMETZ, D. C. (Orgs.). Reformation Theology. Cambridge: CUP, 2004, p. 22-27.

GARCÍA-VILLOSLADA, Ricardo. Martín Lutero, 2. vol. Madrid: BAC, 1976.

GILES, Thomas Ranson. História da Educação. São Paulo: E. P. U., 1987.

GREEN. Vivian Hubert Howard. Renascimento e Reforma: a Europa entre 1450 e 1660. Lisboa: Publicações Dom Quixote, 1984.

JANZ, Denis R. Late medieval theology. In: BAGCHI, David; STEINMETZ, David C. (Org.). Reformation Theology. Cambridge: CUP, 2004, p. 5-14.

JOESTEL, Volkmar; SCHORLEMMER, Friedrich. Wir Sind Allzu Lange Deutsche Bestien Gewesen: volksbildung bei Luther und Melanchthon. Sachsen-Anhalt: Stiftung Luthergedenkstatten, [s.d].

KOLB, Robert. Philipp Melanchthon: reformer and theologian, Concordia Journal: 1997, p. 309-316.

KUROPKA, Nicole. Bitte Aktualisieren. In: DORGERLOH, Stephan (Hg.). Melanchthon. Das Magazin zu seinem. Frankfurt: EKD, 2009.

LARROYO, Francisco. História geral da pedagogia. São Paulo: Editora Mestre Jou, 1982.

LIVRO DE CONCÓRDIA. Confissão de Augsburgo. In: As confissões da Igreja Evangélica Luterana. Porto Alegre: Concórdia, 1980.

LUZURIAGA, Lorenzo. História da educação e da pedagogia. São Paulo: Companhia Editora Nacional, 2001.

MANACORDA, Mario Alighiero. História da educação: da antiguidade aos nossos dias, 3. ed. São Paulo: Cortez, 1992.

MARX, Karl. O capital: crítica da economia política, vol. 1. Posfácio à segunda edição. São Paulo: Abril Cultural, 1983.

MELANCHTHON, Felipe. Orations on Philosophy and Education. Translated by: Christine F. Salazar. Cambridge: Sachiko Kusukawa, 1999.

O’NEILL, Judith. Martín Lutero. Madrid: AKAL, 1991.

REINHARD, Wolfgang. Pressures towards Confessionalization? Prolegomena to a Theory of the Confessional Age. In: DIXON, C. S. The German Reformation: Blackwell Essential Readings. Oxford: Blackwell, 1999, p. 169-192. 
RHEIN, Stefan, et al. Philipp Melanchthon: Biographien zur Reformation, Wittenberg: Drei Kastanien, 1998.

RICHARD, James William. Philip Melanchthon - the protestant preceptor of Germany (1497-1560). New York: Knickerbocker Press, 1898.

RIETH, Ricardo Willy. Filipe Melanchthon (1497-1560), reformador e humanista: síntese de sua contribuição à educação. Logos: Revista de Divulgação Científica. Canoas: Ed. da ULBRA, v. 9, n. 2, p. 35-44, 1997.

RUPP, Horst. PHILIPP MELANCHTON (1497-1560). Revista trimestral de educación comparada, vol. XXVI, n. 3, septiembre 1996, p. 659-669. Disponível em: <http://www. ibe.unesco.org/fileadmin/user_upload/archive/publications/ThinkersPdf/melanchs.pdf $>$ Acesso em: 3 de set. 2012.

SCASE, Wendy. Lollardy. In: BAGCHI, David; STEINMETZ, David C. (Org.). Reformation Theology. Cambridge: CUP, 2004, p. 15-21.

SCHEIBLE, Heinz. Melanchthon: uma biografia. São Leopoldo: Sinodal, 2013.

SILVA, Fabrícia Carla de Albuquerque. As concepções pedagógicas de Filipe Melanchthon nas fermentações do século XVI, 55s. Monografia (Graduação em Pedagogia). Universidade Federal de Alagoas, Maceió, 2010.

TAWNEY, Richard Henry. A Religião e o surgimento do Capitalismo. São Paulo: Perspectiva, 1971.

ULRICH, Claudete Beise, KLUG, João. Felipe Melanchthon (1497-1560): pedagogo da Reforma protestante, patrimônio da educação. Revista Brasileira de História das Religiões. ANPUH, Ano VIII, n. 24, jan./abr. 2016.

VIEIRA, Paulo Henrique. Calvino, Calvinismo e Educação, 123s. Dissertação (Mestrado em Educação). Programa de Pós-Graduação em Educação, Universidade Estadual de Maringá, Maringá, 2005.

VIEIRA, Paulo Henrique. John Knox (1513-1572) e suas contribuições para a educação na Escócia do século XVI, 155s. Tese (Doutorado em Educação). Universidade Estadual de Maringá, Maringá, 2012.

WIATER, Werner. Church and school should have the same doctrine - state, church, and school according to Philip Melanchthon. In: GOLZ, Reinhold; MAYRHOFER (Hrsg). Luther and Melanchthon in the Educational Thought in Central and Eastern Europe. Munster: LIT, 1998, p. 65, 66.

WILSON, George. Philip Melanchthon 1497-1560. London: The Religious Tract Society, 1897.

WRIEDT, Markus. Entre “angst” e confiança: Melanchthon como um homem do século XVI. Disponível em: <http://www.seminarioconcordia.com.br/seminario/documentos/ vox/VC122.pdf> Acesso em: 13 jun. 2011. 
ZULUAGA, Isabel Gutierrez. Historia de la educación. Madrid: Narcea. Ediciones, 1972.

DAdOS DOS AUTORES

\section{Rodrigo Pinto de Andrade}

Doutor em Educação pela Universidade Estadual de Maringá. Docente do Curso de Pedagogia da Universidade Estadual do Paraná. Campo Mourão/PR - Brasil. rodrigouem@ yahoo.com.br

\section{Cézar De Alencar Arnaut de Toledo}

Doutor em Educação pela Universidade Estadual de Campinas. Docente do Departamento de Fundamentos da Educação e do Programa de Pós-Graduação em Educação da Universidade Estadual de Maringá. Maringá/PR - Brasil. caatoledo@uem.br

\section{Francielle Aparecida Garuti de Andrade}

Doutoranda do Programa de Pós-graduação em Educação da Universidade Estadual de Maringá. Maringá/PR - Brasil. garuti_andrade@yahoo.com.br

Submetido em: 29-5-2017

Aceito em:18-12-2017 